\title{
Influence of metal resistant-plant growth-promoting bacteria on the growth of Ricinus communis in soil contaminated with heavy metals
}

\author{
Mani Rajkumar*, Helena Freitas \\ Centre for Functional Ecology, Department of Botany, University of Coimbra, Coimbra 3000-455, Portugal
}

Received 17 August 2007; received in revised form 13 November 2007; accepted 16 November 2007

Available online 15 January 2008

\begin{abstract}
The metal resistant-plant growth-promoting bacterial (PGPB) strains PsM6 and PjM15 isolated from a serpentine soil were characterized as Pseudomonas sp. and Pseudomonas jessenii, respectively, on the basis of their morphological, physiological, biochemical characteristics and 16S rDNA sequences. Assessment of plant growth-promoting parameters revealed the intrinsic ability of the strains for the utilization of 1-aminocyclopropane-1-carboxylic acid as the sole $\mathrm{N}$ source, solubilization of insoluble phosphate and production of indole-3-acetic acid (IAA). Further, a pot experiment was conducted to elucidate the effects of inoculating metal resistant PGPB on the plant growth and the uptake of $\mathrm{Ni}, \mathrm{Cu}$ and $\mathrm{Zn}$ by Ricinus communis. Inoculation of Pseudomonas sp. PsM6 or P. jessenii PjM15 increased the shoot and root biomass of $R$. communis grown in non-contaminated and contaminated soil. However, the maximum biomass was observed in the plants inoculated with strain PjM15. This effect can be attributed to the solubilization of phosphate and production of IAA. Inoculation of Pseudomonas sp. PsM6 and PjM15 did not greatly alter the organ metal concentrations except $\mathrm{Zn}$ which concentration was higher in root, stem and leaf of inoculated plants. The results of metal extraction with PGPB strains showed that PsM6 was more efficient at solubilizing Zn than PjM15, and that PjM15 was better at solubilising Ni and $\mathrm{Cu}$ than PsM6. Owing to its wide action spectrum, the metal resistant PGPB could serve as an effective metal sequestering and growth-promoting bioinoculant for plants in metal-stressed soil. The present study has provided a new insight into the phytoremediation of metal-contaminated soil.
\end{abstract}

(C) 2007 Elsevier Ltd. All rights reserved.

Keywords: Heavy metals; Ricinus communis; PGPB; IAA; Phytoremediation

\section{Introduction}

The continued industrialization of countries has led to extensive environmental problems. A wide variety of chemicals (e.g. heavy metals, pesticides, chlorinated solvents, etc.) have been detected in different biota such soil, water, and air (Cheng, 2003; Turgut, 2003). Heavy metals pose a critical concern to human health and environmental issues due to their high occurrence as a contaminant, low solubility in biota, and the classification of several heavy metals as carcinogenic and mutagenic (Alloway, 1995; Diels et al., 2002). Moreover, the metals cannot be

\footnotetext{
${ }^{*}$ Corresponding author. Tel.: +351 239855243; fax: +351 239855211.

E-mail address: mraaj13@yahoo.com (M. Rajkumar).
}

degraded to harmless products and hence persist in the environment indefinitely. As a result, many different remediation methods have been tried to address the rising number of heavy metal contaminated sites. Most of the traditional methods are either extremely costly (i.e., excavation, solidification and burial) or simply involve the isolation of the contaminated sites. Some methods, such as soil washing, can pose an adverse effect on biological activity, soil structure and fertility, and incur significant engineering costs (Pulford and Watson, 2003). Phytoremediation, the use of hyperaccumulating plants to remove pollutants from the environment or to render them harmless (Raskin et al., 1997), with its lower cost and environmental friendly nature, has received increasing attention in the last decades (Salt et al., 1998). Currently there are a 
number of reports available on metal accumulating plants that are used in removing toxic metals from the soil (Delorme et al., 2001; Whiting et al., 2001; Glick, 2003; Sheng and Xia, 2006). Ricinus communis (castor bean) is one of such plant species, which has attracted considerable attention because of its ability to grow in heavily polluted soil together with its capacity for metal ion accumulation (Prasad and Freitas, 2003; Rockwood et al., 2004; Cecchi and Zanchi, 2005). In addition, $R$. communis is an industrial crop with multiple non-food uses and is an excellent rotation and companion crop. The possibilities of easily growing $R$. communis in different climates and using its biomass in biofuel industries can make heavy metal contaminated soils productive, and, although slowly, restore them at the same time. It signifies economic advantage along with a better quality of soil.

The efficiency of phytoaccumulation may not only depend on the plant itself but also on the interaction of the plant roots with microbes and the concentrations of bio-available metals in soil (Wang et al., 1989). Further, the rhizosphere provides a complex and dynamic microenvironment where microorganisms, in association with roots, form unique communities that have considerable potential for detoxification of hazardous waste compounds (De-Souza et al., 1999). Soil microorganisms can resist toxicity by transforming metals into less toxic forms, by immobilising metals on the cell surface or in intracellular polymers, and by precipitation or biomethylation (Silver, 1996). Certain rhizosphere bacteria have exceptional ability to promote the growth of the host plant by various mechanisms, namely fixation of atmospheric nitrogen, utilization of 1-aminocyclopropane-1carboxylic acid (ACC) as a sole $\mathrm{N}$ source, production of siderophores, or production of plant growth regulators (hormones) (Glick et al., 1998, 1999). In addition, many microorganisms in the soil are able to solubilise "unavailable" forms of heavy metal-bearing minerals by excreting organic acids (Abou-Shanab et al., 2003). Therefore, improvement of the interactions between plants and beneficial rhizosphere microbes can enhance biomass production and tolerance of the plants to heavy metals, and are considered to be an important component of phytoremediation technology (Glick, 2003). Although many soil bacteria are tolerant to heavy metals and play important roles in mobilization or immobilization of heavy metals (Gadd, 1990), only a few attempts have been made to study their role in the tolerance to and uptake of heavy metals by the plants.

Thus the aim of this study was to (1) isolate and characterize heavy metal resistant-plant growth-promoting bacteria (PGPB) from serpentine soils, (2) screen the isolates for auxiliary activities including ACC deaminase activity, solubilisation of insoluble phosphate and production of indole-3-acetic acid (IAA) and (3) elucidate the effects of inoculating metal resistant-PGPB on the plant growth and the uptake of $\mathrm{Ni}, \mathrm{Cu}$ and $\mathrm{Zn}$ by $R$. communis in soil.

\section{Materials and methods}

\subsection{Isolation of metal resistant-PGPB}

The bacterial strains were isolated from a serpentine site in Bragança, north-east of Portugal, previously described by Freitas et al. (2004). For isolation and enumeration of microorganisms, soil samples were serially diluted in sterile distilled water and plated on Luria-Bertani (LB) agar supplemented with $50 \mathrm{mg}^{-1}(\mathrm{ppm})$ level of heavy metals $\mathrm{NiCl}_{2} \cdot 6 \mathrm{H}_{2} \mathrm{O}, \mathrm{CuSO}_{4} \cdot 7 \mathrm{H}_{2} \mathrm{O}$ and $\mathrm{ZnSO}_{4} \cdot 7 \mathrm{H}_{2} \mathrm{O}$ one metal at a time or as heavy metal mixture. The plates were incubated at $27^{\circ} \mathrm{C}$ for $48 \mathrm{~h}$ to screen resistant colonies. To check the extent of resistance, the selected bacterial isolates were grown in LB agar media containing different concentrations of $\mathrm{Ni}, \mathrm{Cu}$ or $\mathrm{Zn}$ ranging from 100 to $1000 \mathrm{mg} \mathrm{l}^{-1}$ (Rajkumar et al., 2005). In order to isolate the PGPB, the heavy metal resistant strains were grown on DF salts minimal medium (Dworkin and Foster, 1958) supplemented with $3 \mathrm{mM}$ ACC to provide a nitrogen source at $27^{\circ} \mathrm{C}$ for $168 \mathrm{~h}$ at $175 \mathrm{rpm}$. The inoculated DF salt minimal medium without ACC was used as a blank. The bacterial growth was monitored as a function of biomass by measuring the optical density at $600 \mathrm{~nm}$ against blank.

\subsection{Molecular characterization of $P G P B$}

The bacterial strains were grown in LB broth at $27^{\circ} \mathrm{C}$. Cells were harvested after $24 \mathrm{~h}$ and processed immediately for DNA isolation using standard procedure (Sambrook et al., 1989). Amplification of 16S rRNA gene sequence was performed by polymerase chain reaction (PCR) with the conserved eubacterial primers pA (5'-AGAGTTTGATCCTGGCTCAG; Escherichia coli bases 8-27) and pC5B (5'-TACCTTGTTACGACTT; E. coli bases 15071492) (Dunbar et al., 1999). Reaction conditions were as described by Branco et al. (2005). Each amplification mixture $(5 \mu \mathrm{l})$ was analysed by agarose gel $(1.5 \% \mathrm{w} / \mathrm{v})$ electrophoresis in TAE buffer $(0.04 \mathrm{M}$ Tris acetate, $0.001 \mathrm{M}$ EDTA) containing $1 \mu \mathrm{g} \mathrm{m}^{-1}$ (w/v) ethidium bromide. For further sequencing reaction, the amplified 16S rDNA was purified from salts and primers using the PCR purification kit (Roche Diagnostics) according to the manufacturer's instructions. Automated sequencing of the purified PCR products was performed using the dRodamina terminator cycle sequencing kit and the ABI 310 DNA Sequencer (Applied Biosystems, Foster City, CA) according to the manufacturer's instructions. Partial 16S rDNA sequences obtained were matched against nucleotide sequences present in GenBank using the BLASTn program (Altschul et al., 1997).

\subsection{Characterization of plant growth-promoting features of $P G P B$}

To determine ACC deaminase activity, the PGPB were grown in test tubes containing $10 \mathrm{ml}$ of DF salts minimal 
medium. The medium was supplemented with $3 \mathrm{mM}$ ACC. After cultivation for $72 \mathrm{~h}$ at $27^{\circ} \mathrm{C}$, the cells were harvested by centrifugation at $9000 \mathrm{rpm}$ for $10 \mathrm{~min}$ at room temperature. The ACC deaminase activity in cells was determined by monitoring the amount of $\alpha$-ketobutylate generated by the enzymatic hydrolysis of ACC as described by Belimov et al. (2005). The protein concentration of cell suspensions was determined by the method of Bradford (1976). IAA production by PGPB was determined according to the method of Bric et al. (1991). Cultures of the isolates were raised in LB broth amended with $500 \mu \mathrm{g}$ of tryptophan $\mathrm{ml}^{-1}$ at $27^{\circ} \mathrm{C}$ for $96 \mathrm{~h}$ at $200 \mathrm{rpm}$. Cells were removed by centrifugation at $6000 \mathrm{rpm}$ and the supernatant was assayed for IAA production. The phosphate solubilizing activity of the isolates was analyzed in NBRIP medium (Nautiyal, 1999) amended with tricalcium phosphate. The isolates were grown at $27^{\circ} \mathrm{C}$ for $192 \mathrm{~h}$ at $200 \mathrm{rpm}$. The solubilized phosphate in the culture supernatant was quantified as detailed by Fiske and Subbarow (1925).

\subsection{Influence of PGPB on R. communis growth and metal uptake}

Soil samples were collected from the Botanical garden, Department of Botany, University of Coimbra, Coimbra, Portugal. The soil properties are listed in Table 1. The soil was sieved $(2 \mathrm{~mm})$ and sterilized by steaming $\left(100^{\circ} \mathrm{C}\right.$ for $1 \mathrm{~h}$ on three consecutive days). The soils were artificially contaminated with $\mathrm{Ni}\left(275 \mathrm{mg} \mathrm{kg}^{-1}\right), \mathrm{Cu}\left(300 \mathrm{mg} \mathrm{kg}^{-1}\right)$ and $\mathrm{Zn}\left(400 \mathrm{mg} \mathrm{kg}^{-1}\right)$ and left in a greenhouse for a 3 week period (for metal stabilization). Seeds of $R$. communis were surface sterilized in $2 \% \mathrm{Ca}(\mathrm{OCl})_{2}(2 \mathrm{~h})$ and rinsed several times with sterile distilled water. The seeds were allowed to germinate in sterilized non-contaminated soil at $25^{\circ} \mathrm{C}$ and a 16/8 day/night regime. For inoculation of the seedlings, bacterial cultures were grown for $18 \mathrm{~h}$, cells harvested by centrifugation $(6000 \mathrm{rpm}, 10 \mathrm{~min})$, washed twice with sterile distilled water, and resuspended in biological saline $(0.85 \% \mathrm{KCl})$. Fifteen-day-old seedlings were soaked for $2 \mathrm{~h}$ in an actively growing bacterial culture $\left(10^{9} \mathrm{CFU} \mathrm{ml}^{-1}\right)$ and transplanted in plastic pot (four plants pot ${ }^{-1}$ ) containing $300 \mathrm{~g}$ of metal contaminated or non-contaminated soil. Each treatment was performed in triplicates. After $35 \mathrm{~d}$ the plants were carefully removed from the pots and the root

Table 1

Selected properties and heavy metals concentrations of the used soil

\begin{tabular}{ll}
\hline Parameters & Content \\
\hline $\mathrm{pH}$ & 5.95 \\
Organic matter $(\%)$ & $4.3^{\mathrm{a}}\left( \pm 0.3^{\mathrm{b}}\right)$ \\
$\mathrm{Metals}\left(\mathrm{HNO}_{3}\right.$ extractable) $\mathrm{mg} \mathrm{kg}^{-1}$ dry soil & \\
$\mathrm{Ni}$ & $15.9( \pm 1.4)$ \\
$\mathrm{Cu}$ & $21.7( \pm 2.6)$ \\
$\mathrm{Zn}$ & $106.6( \pm 5.1)$ \\
\hline
\end{tabular}

${ }^{\mathrm{a}}$ Values represent average of 3 samples except $\mathrm{pH}$.

${ }^{\mathrm{b}}$ Values in parentheses represent standard deviation. surface was cleaned several times with distilled water. Growth parameters such as shoot dry weight and root dry weight of the plants were measured. The accumulation of total $\mathrm{Ni}, \mathrm{Cu}$ and $\mathrm{Zn}$ in root, stem and leaf system were also analysed using atomic absorption spectrophotometer after nitric acid digestion (Freitas et al., 2004).

\subsection{Effects of PGPB on the mobility of soil metals}

Batch studies on the effects of bacteria on the mobility of soil metals were carried out by using $50-\mathrm{ml}$ scaled polypropylene centrifuge tubes. The sterilized soil was artificially contaminated with $\mathrm{Ni}, \mathrm{Cu}$ and $\mathrm{Zn}$ as detailed in earlier section. Pure culture bacterial strains were grown in LB broth and placed on a shaker at $200 \mathrm{rpm}$ and $27^{\circ} \mathrm{C}$. After $24 \mathrm{~h}$, optical density $(600 \mathrm{~nm})$ was measured and adjusted to 1.5; the cultures were centrifuged at $6000 \mathrm{rpm}$ for $10 \mathrm{~min}$, washed in phosphate buffer ( $\mathrm{pH} 7.0$ ) twice, resuspended, washed in sterile water, recentrifuged, and finally resuspended in $5 \mathrm{ml}$ sterile water. Small aliquots of washed bacterial culture (up to $1 \mathrm{ml}$ ) were added to the $1 \mathrm{~g}$ of soil in the centrifuge tubes. Sterile water was added to soil as an axenic control. All tubes were weighed, wrapped in brown paper and placed on an orbital shaker at $200 \mathrm{rpm}$ at $27^{\circ} \mathrm{C}$. After 1 week, the tubes were again weighed to compensate for evaporation of water. Ten milliliters of sterile water were added to each tube to extract the soil water soluble heavy metals. The soil suspensions were centrifuged at $7000 \mathrm{rpm}$ for $10 \mathrm{~min}$ and filtered. The concentrations of $\mathrm{Ni}, \mathrm{Cu}$ and $\mathrm{Zn}$ in the filtrate were determined by atomic absorption spectrophotometer and the mass of tubes and soils was determined immediately.

\subsection{Biosorption of metals by $P G P B$}

The biosorption study was carried out as described by Hernandez et al. (1998) with some modifications. Bacteria were grown in $100 \mathrm{ml}$ of LB broth until reaching 1.0 of optical density $(600 \mathrm{~nm})$. Cells were then harvested by centrifugation at $6000 \mathrm{rpm}$ for $15 \mathrm{~min}$ and the bacterial pellet washed twice with sterile water. The harvested biomass was re-suspended in Eppendorf's tubes containing $1.5 \mathrm{ml}$ of trimetal solution $\left(275 \mathrm{mg} \mathrm{Ni}^{-1}, 300 \mathrm{mg} \mathrm{Cu}^{-1}\right.$ and $400 \mathrm{mg}$ $\mathrm{Zn}^{-1}$ ). After incubation at room temperature for $10 \mathrm{~h}$, the cells were harvested by centrifugation under the same experimental condition. The amount of residual metal present in the supernatant was measured by atomic absorption spectrophotometer.

\section{Results}

\subsection{Isolation of heavy metal resistant $P G P B$}

Thirty seven colonies were screened from initial (50 $\mathrm{mg}^{-1}$ ) level of heavy metal supplemented LB medium. After secondary screening, 7 bacterial strains showing a high degree of metal-resistance were selected for further 
studies. In order to isolate the PGPB, the metal resistant strains were tested for the ability to grow on DF salts minimal medium with ACC. Among the seven strains tested, PsM6 and PjM15 grew in DF salts minimal medium with ACC as the sole source of nitrogen. However, maximum growth was observed in PsM6 compared with PjM15. In the absence of ACC, the strains PsM6 and PjM15 showed a limited growth (Fig. 1).

\subsection{Molecular characterization of $P G P B$}

On the basis of morphological, physiological, biochemical characteristics (data not shown) and comparative analysis of the sequence with already available database showed that the strains PsM6 and PjM15 were close to the members of the genus Pseudomonas. Partial sequence of PsM6 (780 bp) showed 99\% homology with the sequence of Pseudomonas sp. and PjM15 (923 bp) showed 99\% homology with Pseudomonas jessenii. The sequences were deposited at GenBank (Pseudomonas sp. PsM6, accession no. AM707021; Pseudomonas jessenii PjM15, accession no. AM707022).

\subsection{Plant growth-promoting features of $P G P B$}

The metal resistant PGPB strains Pseudomonas sp. PsM6 and PjM15 were assayed for a number of traits thought to be important for plant growth-promoting activity (Table 2). Pseudomonas sp. PsM6 had a high level of ACC deaminase activity, whereas PjM15 exhibited only a low level of activity. Further, Pseudomonas sp.

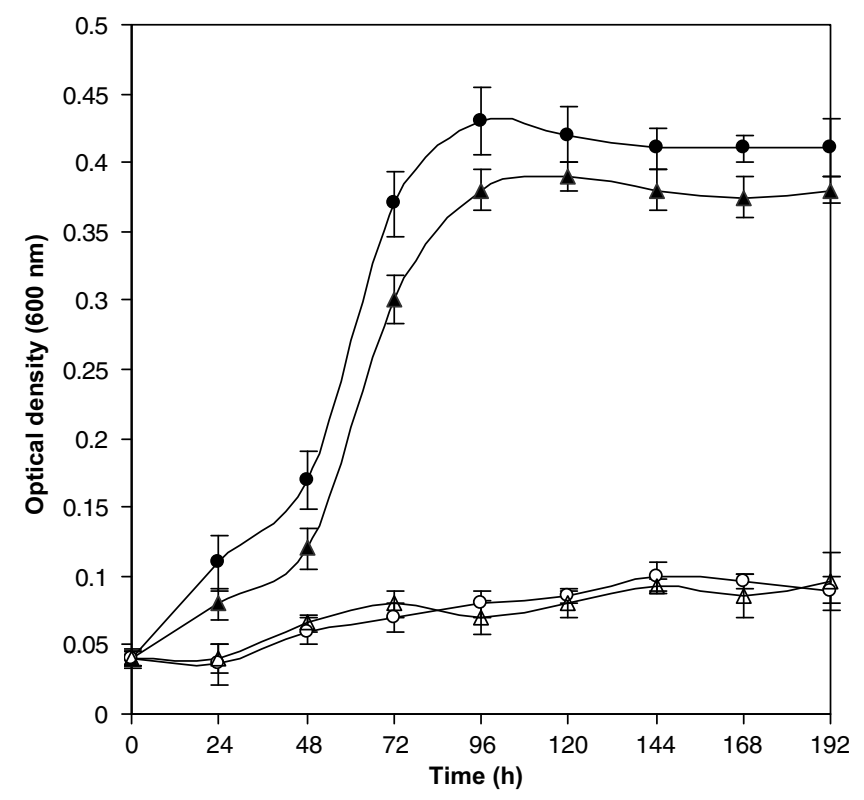

Fig. 1. Growth of PGPB on DF salts minimal medium. Pseudomonas sp. PsM6 with ACC (๑), P. jessenii PjM15 with ACC (ム), Pseudomonas sp. PsM6 without ACC $(\bigcirc)$, P. jessenii PjM15 without ACC $(\triangle)$. Each value is the mean of triplicates. Error bars represent standard deviation.
Table 2

Some key traits of PGPB strains Pseudomonas sp. PsM6 and P. jessenii PjM15

\begin{tabular}{lll}
\hline Parameters & Strain \\
\cline { 2 - 3 } & $\begin{array}{l}\text { Pseudomonas } \mathrm{sp} . \\
\text { PsM6 }\end{array}$ & $\begin{array}{l}\text { P. jessenii } \\
\text { PjM15 }\end{array}$ \\
\hline $\begin{array}{l}\text { ACC deaminase, } \alpha \text {-ketobutyrate } \\
\mathrm{mg}^{-1} \text { protein } \mathrm{h}^{-1}(\mathrm{nmol})\end{array}$ & $66.52^{\mathrm{a}}\left( \pm 7.05^{\mathrm{b}}\right)$ & $34.23( \pm 4.67)$ \\
Phosphate solubilization $\left(\mathrm{mg}^{-1}\right)$ & $73.11( \pm 3.26)$ & $88.67( \pm 4.46)$ \\
IAA synthesis $\left(\mathrm{mg} \mathrm{l}^{-1}\right)$ & $17.74( \pm 2.06)$ & $39.88( \pm 3.68)$ \\
Metal tolerance level $\left(\mathrm{mg}^{-1}\right)$ & & \\
$\mathrm{Ni}$ & 800 & 900 \\
$\mathrm{Cu}$ & 750 & 600 \\
$\mathrm{Zn}$ & 700 & 700 \\
\hline
\end{tabular}

${ }^{\text {a }}$ Values represent average of 3 samples except the metal tolerance levels.

${ }^{b}$ Values in parentheses represent standard deviation.

PsM6 and PjM15 utilized tryptophane as a precursor for their growth and IAA production. The maximum production of IAA was observed in PjM15 compared with PsM6. Similarly, PsM6 and PjM15 utilized tricalcium phosphate as the sole source of phosphate. The strain PjM15 exhibited higher rate of phosphate solubilization than PsM6.

\subsection{Influence of PGPB on the growth of $R$. communis}

In control soil, inoculation of Pseudomonas sp. PsM6 and PjM15 showed an increase in shoot and root dry weight of plant (Fig. 2). However, maximum plant growth-promoting effect was observed in $\mathrm{PjM} 15$, which enhances shoot and root dry weight by $14 \%$ and $19 \%$, respectively, compared with non-inoculated plants. Similarly, PsM6 enhances the shoot dry weight and root dry weight by $7 \%$ and $12 \%$, respectively. The non-inoculated plants grown in metal contaminated soil showed a decrease of $7 \%$ and $3 \%$ in shoot and root dry weight, respectively. In metal contaminated soils, plants inoculated with Pseudomonas sp. PsM6 and PjM15 exhibited an increase in shoot and root dry weight. However, the highest plant growthpromoting effect was found for PjM15, which enhances shoot and root dry weight by $20 \%$ and $25 \%$, respectively. Similarly, PsM6 enhances shoot and root dry weight by $15 \%$ and $18 \%$, respectively.

\subsection{Metal accumulation in R. communis tissues}

The metal concentrations in the root, stem and leaf tissues of $R$. communis grown in artificially metal contaminated soil are given in Table 3. In general, inoculation of Pseudomonas sp. PsM6 and PjM15 did not greatly alter the concentration of metal except $\mathrm{Zn}$ in plant tissues. The concentration of $\mathrm{Zn}$ in root tissues was increased after inoculation with PsM6 and PjM15. However, this effect was higher in PjM15 than PsM6. Further it can be observed that inoculation enhanced the translocation of $\mathrm{Zn}$ from root to shoot. Compared with the control, the 

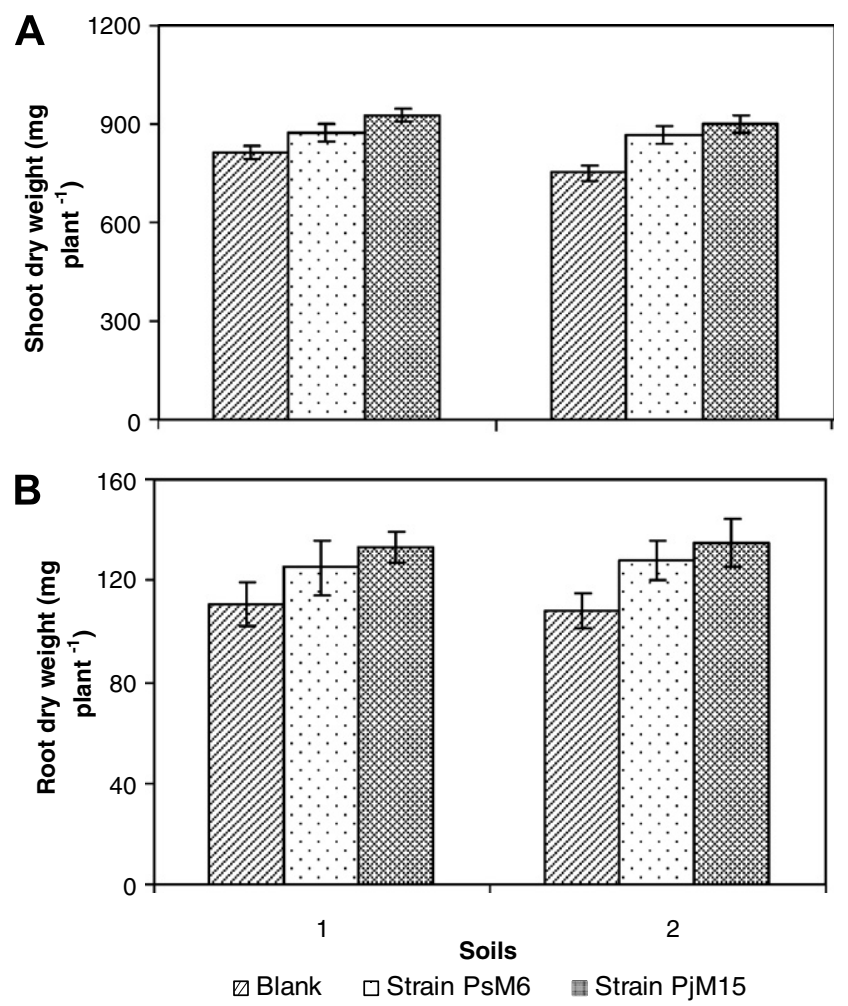

Fig. 2. Effects of inoculation with PGPB strains on shoot (A) and root (B) dry weights of $R$. communis. (1) Non-contaminated soil; (2) metalcontaminated soil. Each value is the mean of triplicates. Error bars represent standard deviation.

Table 3

$\mathrm{Ni}, \mathrm{Cu}$ and $\mathrm{Zn}$ concentrations in $\mathrm{R}$. communis tissues

\begin{tabular}{|c|c|c|c|}
\hline & Root & Stem & Leaf \\
\hline \multicolumn{4}{|c|}{ Nickel concentration $\left(\mathrm{mg} \mathrm{kg}^{-1}\right)$} \\
\hline Blank & $185.0^{\mathrm{a}}\left( \pm 9.8^{\mathrm{b}}\right)$ & $35.0( \pm 4.0)$ & $53.0( \pm 5.2)$ \\
\hline Pseudomonas sp. PsM6 & $166.6( \pm 10.0)$ & $41.3( \pm 3.0)$ & $56.1( \pm 6.6)$ \\
\hline P. jessenii $\mathrm{Pj} \mathrm{M} 15$ & $203.0( \pm 7.2)$ & $44.0( \pm 6.0)$ & $62.3( \pm 4.0)$ \\
\hline \multicolumn{4}{|c|}{ Copper concentration $\left(\mathrm{mg} \mathrm{kg}^{-1}\right)$} \\
\hline Blank & $147.3( \pm 7.5)$ & $12.5( \pm 2.2)$ & $10.4( \pm 1.9)$ \\
\hline Pseudomonas sp. PsM6 & $157.0( \pm 9.1)$ & $15.9( \pm 2.3)$ & $9.6( \pm 1.1)$ \\
\hline P. jessenii $\mathrm{Pj} \mathrm{M} 15$ & $175.6( \pm 7.1)$ & $14.0( \pm 2.3)$ & $13.9( \pm 1.4)$ \\
\hline \multicolumn{4}{|c|}{ Zinc concentration $\left(\mathrm{mg} \mathrm{kg}^{-1}\right)$} \\
\hline Blank & $375.3( \pm 9.6)$ & $105.0( \pm 6.0)$ & $161.6( \pm 4.5)$ \\
\hline Pseudomonas sp. PsM6 & $391.0( \pm 10.8)$ & $138.3( \pm 11.0)$ & $185.0( \pm 7.5)$ \\
\hline P. jessenii $\mathrm{PjM} 15$ & $407.3( \pm 8.6)$ & $121.6( \pm 12.2)$ & $179.3( \pm 4.5)$ \\
\hline
\end{tabular}

${ }^{\text {a }}$ Values represent average of 3 samples.

${ }^{\mathrm{b}}$ Values in parentheses represent standard deviation.

inoculation of Pseudomonas sp. PsM6 and PjM15 increased the concentrations of $\mathrm{Zn}$ in stem and leaf tissues. However, the highest effect was observed in PsM6, which increases the $\mathrm{Zn}$ concentration in the stem and leaf tissues by $32 \%$ and $15 \%$, respectively. Similarly, PjM15 increases the Zn concentrations in stem and leaf tissues by $16 \%$ and $11 \%$, respectively. By contrast, inoculation of PsM6 and PjM15 did not greatly alter the concentrations of $\mathrm{Ni}$ and $\mathrm{Cu}$ in root, leaf and stem tissues.

\subsection{Effects of PGPB on the mobility of soil metals}

The concentrations of water soluble $\mathrm{Ni}, \mathrm{Cu}$ and $\mathrm{Zn}$ in soil were examined to assess the relative efficiency of Pseudomonas sp. PsM6 and PjM15 in enhancing metal solubilisation from the soil. Compared with control treatment, inoculation of Pseudomonas sp. PsM6 and PjM15 for $7 \mathrm{~d}$ increased the concentrations of soluble heavy metals in soil (Fig. 3). The inoculation of Pseudomonas sp. PsM6 increased the concentrations of soluble $\mathrm{Ni}, \mathrm{Cu}$ and $\mathrm{Zn}$ in soil, which were 2-, 2.7- and 7.4-folds higher than those in the control soil, respectively. Similarly, PjM15 increased the concentrations of soluble $\mathrm{Ni}, \mathrm{Cu}$ and $\mathrm{Zn}$ in soil by 2.4-, 3.2- and 4.93-folds, respectively.

\subsection{Biosorption of metals by $P G P B$}

The data expressing the capabilities of Pseudomonas sp. PsM6 and PjM15 to uptake $\mathrm{Ni}, \mathrm{Cu}$ and $\mathrm{Zn}$ are given in Table 4. It is clearly evident that the isolates exhibited different biosorption capacity towards the tested metal ions. The maximum biosorption by Pseudomonas sp. PsM6 and PjM15 was achieved after $6 \mathrm{~h}$ of incubation. Further incubation up to $10 \mathrm{~h}$ did not improve the extent of biosorption (data not shown). The maximum biosorption capacity for $\mathrm{Cu}$ and $\mathrm{Zn}$ was observed in the case of $\mathrm{PjM} 15$, and the highest quantity of $\mathrm{Ni}$ was adsorbed by PsM6.

\section{Discussion}

Bacteria present in serpentine soil and their interaction with hyperaccumulating plants have attracted the attention of several investigators (Mengoni et al., 2001; Pal et al., 2005) due to biotechnological applications for bioremediation. The serpentine areas are considered as an interesting model for the evolution of metal resistant microorganisms,

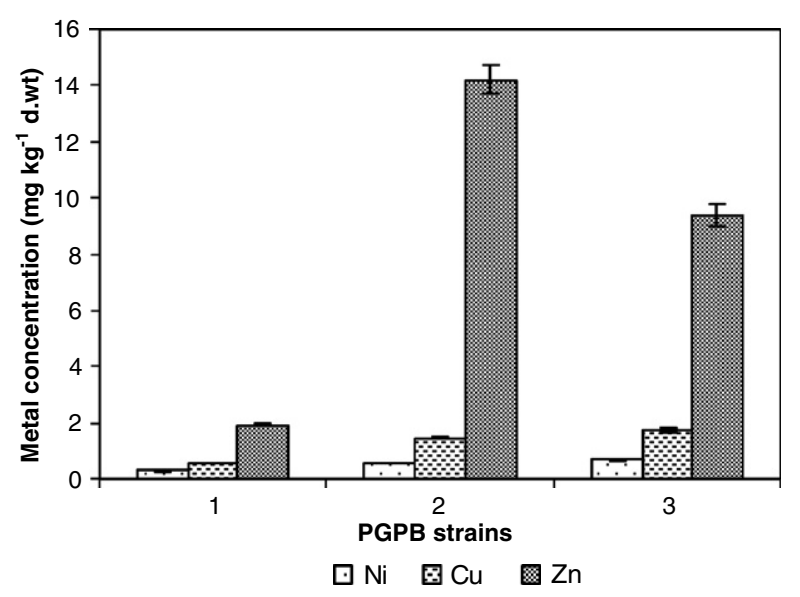

Fig. 3. Effects of inoculation with PGPB strains on the solubilization of Ni, Cu and Zn in soil. (1) Blank; (2) Pseudomonas sp. PsM6; (3) P. jessenii $\mathrm{PjM} 15$. Each value is the mean of triplicates. Error bars represent standard deviation. 
Table 4

Biosorption of Ni, Cu and $\mathrm{Zn}$ by Pseudomonas sp. PsM6 and P. jessenii PjM15 at different time intervals

\begin{tabular}{|c|c|c|c|c|c|c|}
\hline \multirow[t]{3}{*}{ Metal } & \multicolumn{6}{|c|}{ Biosorption of metal ion $\left(\mathrm{mg} \mathrm{g}^{-1}\right.$ dry cell $)$} \\
\hline & \multicolumn{3}{|c|}{ Pseudomonas sp. PsM6 } & \multicolumn{3}{|c|}{ P. jessenii $\mathrm{PjM} 15$} \\
\hline & $2 \mathrm{~h}$ & $4 \mathrm{~h}$ & $6 \mathrm{~h}$ & $2 \mathrm{~h}$ & $4 \mathrm{~h}$ & $6 \mathrm{~h}$ \\
\hline $\mathrm{Cu}$ & $4.32( \pm 0.11)$ & $5.47( \pm 0.08)$ & $5.52( \pm 0.16)$ & $8.08( \pm 0.05)$ & $9.19( \pm 0.23)$ & $10.22( \pm 0.31)$ \\
\hline $\mathrm{Zn}$ & $1.64( \pm 0.08)$ & $2.68( \pm 0.15)$ & $3.66( \pm 0.09)$ & $1.36( \pm 0.08)$ & $3.84( \pm 0.11)$ & $4.39( \pm 0.09)$ \\
\hline
\end{tabular}

${ }^{\text {a }}$ Values represent average of 3 samples.

${ }^{\mathrm{b}}$ Values in parentheses represent standard deviation.

completely different from that of artificially contaminated soils. In recent years, such newer strains and new genetic determinants for heavy metal-resistance could be exploited in bioremediation practices. In this investigation, the bacterial strains were isolated from serpentine soils with an objective to assess the effects of metal resistant PGPB on the plant growth and the uptake of $\mathrm{Ni}, \mathrm{Cu}$ and $\mathrm{Zn}$ by $R$. communis. Among the 7 metal resistant strains tested, Pseudomonas sp. PsM6 and $P$. jessenii PjM15 grew in DF salts minimal medium with ACC as the sole source of nitrogen. Bacterial strains utilizing ACC as a sole source of nitrogen possess ACC deaminase which hydrolyses ACC and enhance the elongation of plant roots (Glick et al., 1998). Certain heavy metal resistant bacterial strains potentially hydrolyse ACC and promote the plant growth. Nickel resistant Kluyvera ascorbata isolated from soil contaminated with $\mathrm{Ni}$ and other heavy metals has been shown to promote plant growth (Burd et al., 2000). Similarly, Belimov et al. (2005) isolated cadmium-resistant Variovorax paradoxus from the rhizosphere of Brassica juncea for promoting plant growth. The PGPB strains Pseudomonas sp. PsM6 and PjM15 exhibited a higher metal tolerance when cultivated under increasing metal levels in the growth medium (Table 2). This high tolerance to heavy metals could be attributed to the fact that the bacteria were isolated from a serpentine soil containing high levels of metals (Freitas et al., 2004). It is known that microorganisms isolated from natural environments contaminated with heavy metals often exhibit tolerance to multiple pollutants because they have adapted to such environments (Pal et al., 2005).

Inoculation of metal resistant PGPB increased the growth of $R$. communis plants and it seemed it was effective in protecting plants from growth inhibition caused by heavy metals. Previously, Doelman (1985) has reported that the efficiency of revegetation and phytoremediation of heavy metal-contaminated sites is closely related to the presence of higher proportions of metal resistant microbial populations in the soil, which likely conferred a better nutritional assimilation and protection effect on plants. In general the metal resistant rhizosphere bacteria have exceptional ability to protect the host plants from metal toxicity by several possible mechanisms. The bestknown mechanism is the utilization ACC by rhizosphere bacteria. A number of PGPB, which stimulate the growth of different plant species (Burd et al., 2000; Belimov et al.,
2002; Rajkumar et al., 2006), contain the enzyme ACC deaminase, which hydrolyses ACC (the immediate precursor of the plant hormone ethylene). Some of the plant ACC is exuded from roots or seeds and cleaved by ACC deaminase to $\mathrm{NH}_{3}$ and $\alpha$-ketobutyrate (Penrose and Glick, 2001). The bacteria utilize the $\mathrm{NH}_{3}$ evolved from $\mathrm{ACC}$ as a source of $\mathrm{N}$ and thereby decrease ACC within the plant with the concomitant reduction of plant ethylene (Grichko and Glick, 2001). In the present study, in addition to ACC deaminase activity, Pseudomonas sp. PsM6 and PjM15 exhibited the solubulization of phosphate and production of IAA (Table 2). In general the elevated levels of heavy metals in soil interfere with uptake of nutrients such as $\mathrm{P}$ and lead to plant growth retardation (Halstead et al., 1969). This deficiency can be compensated by the phosphate-solubilizing ability of PGPB strains (Gupta et al., 2002; Zaidi et al., 2006). Further, the IAA produced by PGPB promotes root growth by directly stimulating plant cell elongation or cell division (Glick et al., 1998). A low level of IAA produced by rhizosphere bacteria promotes primary root elongation whereas a high level of IAA stimulates lateral and adventitious root formation but inhibit primary root growth (Xie et al., 1996). Thus PGPB can facilitate plant growth by altering the plant hormonal balance. The phytohormone IAA production offers great promise for sustaining the increased crop productivity. The metal resistant bacteria belonging to different genera such as Pseudomonas, Mycobacterium, Agrobacterium and Arthrobacter were found to have plant growth-promoting features that can potentially promote plants growth and reduce stress symptoms in plants (Dell'Amico et al., 2005; Rajkumar et al., 2005). The maximum plant growth promotion by $P$. jessenii PjM15 observed in the present study can be attributed to the solubilisation of phosphate and production of IAA.

The process of metal uptake and accumulation by different plants depends on the concentration of available metals in soils, solubility sequences and the plant species (Gupta and Sinha, 2006). The rhizosphere microbes can affect trace metal mobility and availability to the plant, they can produce siderophores for ensuring iron availability, reduce soil $\mathrm{pH}$, and or solubilize phosphates (Smith and Read, 1997; Sheng and Xia, 2006; Zaidi et al., 2006). In the present study, inoculation with Pseudomonas sp. PsM6 or P. jessenii PjM15 did not greatly influence the quantity of accumu- 
lation of metals in root and shoot system. However, on average, only in the case of $\mathrm{Zn}$, was the metal concentration higher in stem and leaves of inoculated plants. Similar observations have also reported by Whiting et al. (2001), who found that the addition of a mixed inoculum of Microbacterium saperdae, Pseudomonas monteilii, and Enterobacter cancerogenes to surface sterilized seeds of Thalaspi caerulescens sown in autoclaved soil increased the $\mathrm{Zn}$ concentration in shoots 2-fold compared with non-inoculated controls; the total accumulation of $\mathrm{Zn}$ was enhanced 4fold. The increased accumulation of $\mathrm{Zn}$ in presence of Pseudomonas sp. PsM6 or P. jessenii PjM15 might be due to more $\mathrm{Zn}$ uptake under acidic soil conditions, which develops as a result of activity of phosphate solubilization in soil. Effects of $\mathrm{pH}$ on the solubility and speciation of metals are well documented (Gadd, 2001; Gadd and Sayer, 2000). Sheng and Xia (2006) reported that the addition of Cd-resistant bacterial strains to Brassica napus grown in metal contaminated soil significantly increased the plant uptake of Cd when compared with the non-inoculated controls as a result of $\mathrm{pH}$ reduction. Similarly, Delorme et al. (2001) hypothesized that soil acidification in the rhizosphere of $T$. caerulescens facilitates metal ion uptake by increasing metal ion mobility around the roots. Our results indicate that bacteria facilitated the release of $\mathrm{Zn}$ from the non-soluble phases in the soil, thus enhancing the availability of $\mathrm{Zn}$ to $R$. communis. This result is in good agreement with the value shown in Fig. 3 concerning bacterial metal solubilisation in the soils. The higher water soluble $\mathrm{Zn}$ induced by Pseudomonas sp. PsM6 inoculation resulted in a correspondingly higher $\mathrm{Zn}$ accumulation in both the shoots and roots of $R$. communis suggesting that the bioavailability of $\mathrm{Zn}$ was increased by through bacterial metabolic activities or their interactions with the plants.

The results obtained here indicate that inoculation of metal resistant PGPB seemed to be very effective in protecting plants from growth inhibition caused by metals, and this was strongly supported by the root and shoot biomass data. The increase in plant growth caused by PGPB may be attributed to the maximum production of IAA and solubilisation of phosphate. In addition, the PGPG exhibited a high degree of metal biosorption potential (Table 4). Bacteria have a high surface area to volume ratio (Beveridge, 1988) and, as a strictly physical cellular interface, should have a high capacity for sorbing metals from solutions (Mullen et al., 1989). Several investigations have shown that relatively large quantities of metallic cations are complexed by fungi (Zhou, 1999) and bacteria (Samuelson et al., 2000). With this intrinsic characteristic, the PGPB may also contribute in reducing the phytotoxic effects of the metals by sharing the metal load due to its demonstrated ability of biosorption and bioaccumulation (Zaidi and Musarrat, 2004). To the best of our knowledge, this is the first report elucidating the role of metal resistant serpentine isolates in heavy metal accumulation by $R$. соттunis with concurrent reduction of metal phytotoxicity and promotion of plant growth.

\section{Conclusions}

The accumulation and distribution of metals in the plant tissue are important aspects to evaluate the role of plants in remediation of contaminated sites (Salt et al., 1998). The results of the present study revealed that inoculation of metal resistant PGPB Pseudomonas sp. PsM6 and $P$. jessenii PjM15 increases the efficiency of phytoextraction directly by enhancing the metal accumulation in plant tissues (especially $\mathrm{Zn}$ ) and indirectly by promoting the shoot and root biomass of $R$. communis. The use of these metal resistant PGPB can be considered as a biotechnological tool of great economical and ecological relevance. As the technology of metal 'phytomining' matures and is commercially developed, even small increases in metal uptake can have very significant impacts on profitability. Thus, suitable modification of the roots/rhizosphere system of heavy metal phytoaccumulators with beneficial microflora could promote metal bioavailability and phytoextraction. Further research will be aimed to assess the suitability of metal resistant PGPB for efficient bioremediation of heavy metals in natural ecosystem.

\section{Acknowledgments}

M. Rajkumar thanks the Portuguese Foundation for Science and Technology (FCT) for awarding a Post-doctoral research Grant (SFRH/BPD/21309/2005). Part of the work has been carried out under the auspices of GRICES (MCTES), Portugal.

\section{References}

Abou-Shanab, R.A., Angle, J.S., Delorme, T.A., Chaney, R.L., van Berkum, P., Moawad, H., Ghanem, K., Ghozlan, H.A., 2003. Rhizobacterial effects on nickel extraction from soil and uptake by Alyssum murale. New Phytol. 158, 219-224.

Alloway, B.J., 1995. Heavy Metal in Soils, second ed. Chapman \& Hall, London.

Altschul, S.F., Madden, T.L., Schaffer, A.A., Zhang, J., Zhang, Z., Miller, W., Lipman, D.J., 1997. Gapped BLAST and PSIBLAST: a new generation of protein database search programs. Nucleic Acids Res. 25, 3389-3402.

Belimov, A.A., Hontzeas, N., Safronova, V.I., Demchinskaya, S.V., Piluzza, G., Bullitta, S., Glick, B.R., 2005. Cadmium-tolerant plant growth-promoting bacteria associated with the roots of Indian mustard (Brassica juncea LCzern.). Soil Biol. Biochem. 37, 241-250.

Belimov, A.A., Safronova, V.I., Mimura, T., 2002. Response of spring rape to inoculation with plant growth-promoting rhizobacteria containing 1-aminocyclopropane-1-carboxylate deaminase depends on nutrient status of the plant. Can. J. Microbiol. 48, 189-199.

Beveridge, T.J., 1988. The bacterial surface: general considerations towards design and function. Can. J. Microbiol. 34, 363-372.

Bradford, M.M., 1976. A rapid and sensitive method for the quantitation of microgram quantities of protein utilizing the principle of protein dye binding. Anal. Biochem. 72, 248-254.

Branco, R., Chung, A.P., Veríssimo, A., Morais, P.V., 2005. Impact of chromium-contaminated wastewaters on the microbial community of a river. FEMS Microbiol. Ecol. 54, 35-46.

Bric, J.M., Bostock, R.M., Silversone, S.E., 1991. Rapid in situ assay for indole acetic acid production by bacteria immobilization 
on a nitrocellulose membrane. Appl. Environ. Microb. 57, 535538.

Burd, G.I., Dixon, D.G., Glick, B.R., 2000. Plant growth promoting bacteria that decreases heavy metal toxicity in plants. Can. J. Microbiol. 46, 237-245.

Cecchi, C.G.S., Zanchi, C., 2005. Phytoremediation of soil polluted by nickel using agricultural crops. Environ. Manage. 36, 675-681.

Cheng, S., 2003. Heavy metal pollution in China: origin, pattern and control. Environ. Sci. Pollut. Res. 10, 192-198.

Dell'Amico, E., Cavalca, L., Andreoni, V., 2005. Analysis of rhizobacterial communities in perennial Graminaceae from polluted water meadow soil, and screening of metal-resistant, potentially plant growth-promoting bacteria. FEMS Microbiol. Ecol. 52, 153162.

Delorme, T.A., Gagliardi, J.V., Angle, J.S., Chaney, R.L., 2001. Influence of the zinc hyperaccumulator Thlaspi caerulescens J. \& C. Presl. and the nonmetal accumulator Trifolium pratense $\mathrm{L}$. on soil microbial population. Can. J. Microbiol. 67, 190-197.

De-Souza, M.P., Huang, C.P.A., Chee, N., Terry, N., 1999. Rhizosphere bacteria enhance that accumulation of selenium and mercury in wetland plants. Planta 209, 259-263.

Diels, L., van der Lelie, N., Bastiaens, L., 2002. New development in treatment of heavy metal contaminated soils. Rev. Environ. Sci. Biotechnol. 1, 75-82.

Doelman, P., 1985. Resistance of soil microbial communities to heavy metals. In: Jensen, V., Kjoelles, A., Soerensen, L.H. (Eds.), Microbial Communities in Soil. Elsevier, London, pp. 369-384.

Dunbar, J., Takala, S., Barns, S.M., Davis, J.A., Kuske, C.R., 1999. Levels of bacterial community diversity in four arid soils compared by cultivation and 16S rRNA gene cloning. Appl. Environ. Microb. 65, 1662-1669.

Dworkin, M., Foster, J., 1958. Experiments with some microorganisms which utilize ethane and hydrogen. J. Bacteriol. 75, 592-601.

Fiske, C.H., Subbarow, Y., 1925. A colorimetric determination of phosphorus. J. Biol. Chem. 66, 375-400.

Freitas, H., Prasad, M.N.V., Pratas, J., 2004. Analysis of serpentinophytes from north-east of Portugal for trace metal accumulationrelevance to the management of mine environment. Chemosphere $54,1625-1642$.

Gadd, G.M., 1990. Heavy metal accumulation by bacteria and other microorganisms. Experientia 46, 834-840.

Gadd, G.M., 2001. Metal transformations. In: Gadd, G.M. (Ed.), Fungi in Bioremediation. Cambridge University Press, Cambridge, UK, pp. 359-382.

Gadd, G.M., Sayer, J.A., 2000. Fungal transformations of metals and metalloids. In: Lovley, D.R. (Ed.), Environmental Microbe-Metal Interactions. American Society for Microbiology, Washington, DC, pp. 237-256.

Glick, B.R., 2003. Phytoremediation: synergistic use of plants and bacteria to clean up the environment. Biotechnol. Adv. 21, 383-393.

Glick, B.R., Patten, C.L., Holguin, G., Penrose, G.M., 1999. Biochemical and Genetic Mechanisms Used by Plant Growth Promoting Bacteria. Imperial College Press, London.

Glick, B.R., Penrose, D.M., Li, J., 1998. A model for the lowering of plant ethylene concentrations by plant growth-promoting bacteria. J. Theor. Biol. 190, 63-68.

Grichko, V.P., Glick, B.R., 2001. Amelioration of flooding stress by ACC deaminase-containing plant growth-promoting bacteria. Plant Physiol. Biochem. 39, 11-17.

Gupta, A.K., Sinha, S., 2006. Chemical fractionation and heavy metals accumulation in the plants of Sesamum indicum (L.) var. T55 grown on soil amended with tannery sludge: selection of single extractants. Chemosphere 64, 161-173.

Gupta, A., Meyer, J.M., Goel, R., 2002. Development of heavy metal resistant mutants of phosphate solubilizing Pseudomonas sp. NBRI4014 and their characterization. Curr. Microbiol. 45, 323327.
Halstead, R.L., Finn, B.J., MacLean, A.J., 1969. Extractibility of nickel added to soils and its concentration in plants. Can. J. Soil Sci. 49, 335342 .

Hernandez, A., Mellado, R.P., Martinez, J.L., 1998. Metal accumulation and vanadium-induced multidrug resistance by environmental isolates of Escherichia hermannii and Enterobacter cloacae. Appl. Environ. Microb. 64, 4317-4320.

Mengoni, A., Barzanti, R., Gonneli, C., Gabbrielli, R., Bazzicalupo, M., 2001. Characterization of nickel-resistant bacteria isolated from serpentine soil. Environ. Microbiol. 3, 691-708.

Mullen, M.D., Wolf, D.C., Ferris, F.G., Beveridge, T.J., Flemming, C.A., Bailey, G.W., 1989. Bacterial sorption of heavy metals. Appl. Environ. Microb. 55, 3143-3149.

Nautiyal, C.S., 1999. An efficient microbiological growth medium for screening phosphate solubilizing microorganisms. FEMS Microbiol. Lett. 170, 265-270.

Pal, A., Dutta, S., Mukherjee, P.K., Paul, A.K., 2005. Occurrence of heavy metal-resistance in microflora from serpentine soil of Andaman. J. Basic Microbiol. 45, 207-218.

Penrose, D.M., Glick, B.R., 2001. Levels of 1-aminocyclopropane-1carboxylic acid (ACC) in exudates and extracts of canola seeds treated with plant growth-promoting bacteria. Can. J. Microbiol. 47, 368-372.

Prasad, M.N.V., Freitas, H., 2003. Metal hyperaccumulation in plants biodiversity prospecting for phytoremediation technology. Electron. J. Biotechn. 6, 285-321.

Pulford, I.D., Watson, C., 2003. Phytoremediation of heavy metal contaminated land by trees - a review. Environ. Int. 29, 529540 .

Rajkumar, M., Nagendran, R., Lee, K.J., Lee, W.H., 2005. Characterization of a novel $\mathrm{Cr}^{6+}$ reducing Pseudomonas sp. with plant growthpromoting potential. Curr. Microbiol. 50, 266-271.

Rajkumar, M., Nagendran, R., Lee, K.J., Lee, W.H., Kim, S.Z., 2006. Influence of plant growth promoting bacteria and $\mathrm{Cr}^{6+}$ on the growth of Indian mustard. Chemosphere 62, 741-748.

Raskin, I., Smith, R.D., Salt, D.E., 1997. Phytoremediation of metals: using plants to remove pollutants from the environment. Curr. Opin. Biotechnol. 8, 221-226.

Rockwood, D.L., Naidu, C.V., Carter, D.R., Rahmani, M., Spriggs, T.A., Lin, C., Alker, G.R., Isebrands, J.G., Segrest, S.A., 2004. Shortrotation woody crops and phytoremediation: opportunities for agroforestry?. Agrofores. Sys. 61 51-63.

Salt, D.E., Smith, R.D., Raskin, I., 1998. Phytoremediation. Annu. Rev. Plant Physiol. Plant Mol. Biol. 13, 468-474.

Sambrook, J., Fritsch, E.F., Maniatis, T., 1989. Molecular Cloning; A Laboratory Manual, second ed. Cold Spring Harbor Laboratory Press, Cold Spring Harbor.

Samuelson, P., Wernérus, H., Svedberg, M., Stahl, S., 2000. Staphylococcal surface display of metal-binding polyhistidyl peptides. Appl. Environ. Microb. 66, 1243-1248.

Sheng, X.F., Xia, J.J., 2006. Improvement of rape (Brassica napus) plant growth and cadmium uptake by cadmium-resistant bacteria. Chemosphere 64, 1036-1042.

Silver, S., 1996. Bacterial resistance to toxic metal ions - a review. Gene 179, 9-19.

Smith, S.E., Read, D.J., 1997. Mycorrhizal Symbiosis. Academic Press, London.

Turgut, C., 2003. The contamination with organochlorine pesticides and heavy metals in surface water in Kucuk Menderes River in Turkey, 2000-2002. Environ. Int. 29, 29-32.

Wang, P.C., Mori, T., Komori, K., Sasatsu, M., Toda, K., Ohtake, H., 1989. Isolation and characterization of an Enterobacter cloacae strain that reduces hexavalent chromium under anaerobic conditions. Appl. Environ. Microb. 55, 1665-1669.

Whiting, S.N., de Souza, M.P., Terry, N., 2001. Rhizosphere bacteria mobilize Zn for hyperaccumulation by Thlaspi caerulescens. Environ. Sci. Technol. 15, 3144-3150. 
Xie, H., Pasternak, J.J., Glick, B.R., 1996. Isolation and characterization of mutants of the plant growth-promoting rhizobacterium Pseudomonas putida GR 12-2 that overproduce indoleacetic acid. Curr. Microbiol. 32, 67-71.

Zaidi, S., Musarrat, J., 2004. Characterisation and nickel sorption kinetics of a new metal hyper-accumulator Bacillus sp.. J. Environ. Sci. Health A 39, 681-691.
Zaidi, S., Usmani, S., Singh, B.R., Musarrat, J., 2006. Significance of Bacillus subtilis strain SJ-101 as a bioinoculant for concurrent plant growth promotion and nickel accumulation in Brassica juncea. Chemosphere 64, 991-997.

Zhou, J.L., 1999. Zn biosorption by Rhizopus arrhizus and other fungi. Appl. Microbiol. Biot. 51, 686-693. 